\title{
Infectiousness of Places: Impact of Multiscale Human Activity Places in the Transmission of COVID-19
}

Lun Liu ( $D$ liu.lun@pku.edu.cn )

Peking University

Hui Wang

Tsinghua University

Zhu Zhang

Peking University

Weiyi Zhang

Peking University

Shengsheng Zhuang

Peking Union Medical College

Shenhao Wang

Massachusetts Institute of Technology

Elisabete A Silva

University of Cambridge

Tingmiao Lv

Peking University

Chi On Chio

Peking University

Yifan Wang

Peking University

Rina Dao

Peking University

Chuchang Tang

Peking University

On leng Ao-leong

Peking University

\section{Research Article}

Keywords: 
Posted Date: February 23rd, 2022

DOI: https://doi.org/10.21203/rs.3.rs-1361344/v1

License: (c) (i) This work is licensed under a Creative Commons Attribution 4.0 International License. Read Full License 


\title{
Infectiousness of places: Impact of multiscale human activity places in the transmission of COVID-19
}

Authors: Lun Liu ${ }^{1,2 *}$, Hui Wang ${ }^{3 *}$, Zhu Zhang ${ }^{1}$, Weiyi Zhang ${ }^{1}$, Shengsheng Zhuang ${ }^{4}$, Shenhao Wang ${ }^{5,6}$, Elisabete A Silva ${ }^{7,8}$, Tingmiao $\mathrm{Lv}^{1}$, Chi On Chio ${ }^{1}$, Yifan Wang ${ }^{1}$, Rina Dao ${ }^{1}$, Chuchang Tang $^{1}$, On Ieng Ao-Ieong ${ }^{1}$

\section{Affiliations:}

${ }^{1}$ School of Government, Peking University; Beijing, China.

${ }^{2}$ Institute of Public Governance, Peking University; Beijing, China.

${ }^{3}$ School of Architecture, Tsinghua University; Beijing, China.

${ }^{4}$ Peking Union Medical College; Beijing, China.

${ }^{5}$ Department of Urban Studies and Planning, Massachusetts Institute of Technology; Cambridge, United States.

${ }^{6}$ Media Lab, Massachusetts Institute of Technology; Cambridge, United States.

${ }^{7}$ Department of Land Economy, University of Cambridge; Cambridge, United Kingdom.

${ }^{8}$ Lab of Interdisciplinary Spatial Analysis, University of Cambridge; Cambridge, United Kingdom.

*Correspondence authors. Email: liu.lun@ pku.edu.cn,wh-sa@mail.tsinghua.edu.cn

\begin{abstract}
COVID-19 raises attention to epistemological risks related to everyday human activities. Our work quantifies infection transmission risks at different human activity places, including different types of settlements at macro-scale and establishments (restaurants, bars, etc.) at micro-scale, using evidences from COVID-19 in 906 urban areas across four continents. Relatively stable rules of how infection risks are distributed across human settlements and establishments are found. At micro-scale, the infection transmission risks at various establishments differ across countries, but generally, physical activity, entertainment and catering establishments lead to more infections than other activity places. At macro-scale, contrary to common beliefs, we find consistent pattern that transmission does not increase with settlement size and density. When considering interaction between the two scales, there is also consistent pattern that a smaller proportion of infections take place at specific establishments in larger settlements, suggesting that general public spaces such as streets play a greater role in transmission due to longer trips. Though with limitations, our work provides the first steps towards a system of knowledge on the linkage between places, human activities and disease transmission.
\end{abstract}




\section{Introduction}

Humans continue to migrate to large, dense urban settlements in the past century. The consequent growth of cities brings benefits such as economies of scale and knowledge spillovers, but also increases the vulnerability of daily life to risks related to people's agglomeration and interaction such as congestion, crime and infectious disease ${ }^{1,2}$, for which COVID-19 is a prominent example. In the spread of these risks, places containing different activities are key risk units that link physical environments, human activities and risk factors. To understand the impact of different places in risk transmission would be important for the science and practice in enhancing the resilience and life quality of human settlements.

The strike of COVID-19 raises the concern on the epistemological risks of places, which however is seldom evaluated. In theory, different types of activity places could lead to different chances of virus transmission. At macro-scale, dense settlements lead to physical proximity among residents, and large settlements connect more people—both might generate more contacts and increase the dissemination of infectious diseases ${ }^{3-5}$. At micro-scale, different types of establishments, such as restaurants, museums, sports fields, are also likely to generate different chances of virus transmission, influenced by the contacts made through corresponding activities and the physical environments. This paper therefore aims to quantify the virus transmission risks associated with different settlement characteristics at macro-scale and establishments at microscale as well as their interactions, to build a system of knowledge on the infectiousness of human activity places and inform relevant policy making.

Though the risk of virus transmission at different types of places can be evaluated with mechanistic modelling ${ }^{6,7}$, it is difficult to capture all human interactions in the simulation. 
Alternatively, we take advantage of the natural experiments provided by the diverse government interventions including the closure of many activity places across regions and countries in COVID-19 and examine the role of places in virus transmission with natural experimental methods. Although there have been a body of research using these empirical data to estimate the efficacy of government interventions in COVID-19, they focus on broad intervention categories instead of specific places ${ }^{8-18}$. In this work, we examine the impacts of two macro-scale place characteristics, population size and density, which have been found to affect many social quantities $^{5,19}$, and eleven common micro-scale establishments, that are schools, childcare centers, offices, non-essential retails, restaurants, bars, entertainment venues, cultural venues, religious venues, indoor sports venues and outdoor sports grounds (detailed descriptions in Table S1). We use four countries from four continents as study cases, which are Japan in Asia, the United Kingdom in Europe, the United States in North America and Brazil in South America. The four countries are diverse in settlements' spatial form, lifestyle, culture and government's actions in COVID-19, which could enhance the generalizability of our findings.

We employ a natural experiment-based econometric approach called difference-in-differences (DiD), which is widely used in examining causal relationship in social sciences and estimates the causal impact of a treatment through differences in treatment timing in different units ${ }^{20}$. To be more specific, for estimating the impact of a group of establishments in virus transmission, the DiD method subtracts the course of epidemic in spatial units where that group of establishments get closed or reopened with the epidemic course in spatial units where the status of the same establishments remain unchanged, assuming that the epidemic in the two groups should move in parallel trend absence of the change. By subtracting the trends, this method can rule out the 
influence of simultaneous behavioral changes shared by all spatial units, which could otherwise be falsely attributed to the status change of establishments thus inflate the estimates ${ }^{10}$.

The choice of spatial units in each sample country is based on two criteria: first, infection data and other socioeconomic data are available for the spatial units; and second, the spatial units are as close as possible to the spatial extents of settlements (a continuously built-up area). Spatial units with a population larger than 100,000 are taken as samples, as smaller units may not have enough infection cases to produce reliable estimates. These criteria lead to 45 spatial units in Japan, 234 in the United Kingdom, 308 in the United States and 319 in Brazil after cleaning missing data (detailed explanations on the choice of spatial units in Section S1.1-1.4).

We start from evaluating the risks of virus transmission at different types of establishments, through estimating the causal impacts of establishment closures on the course of the epidemic. This is implemented by modelling the relationship between instantaneous reproduction numbers $\left(R_{t}\right)$ in the spatial units and the status of various establishments, controlling for other interventions (stay-at-home orders and gathering bans). We estimate separate models for each country to allow for heterogeneous infection risks at various establishments in different countries, considering cross-country differences in lifestyle, culture, urban form, etc. Correlation analysis shows that the Kendall's correlation coefficients between the status of establishments are mostly lower than 0.8 in our data set, despite that in some cases governments close or reopen multiple types of establishments together (Fig. 1), providing at least 180 unit-day differences between the status of any pair of establishments. We also verify that the estimates are not sensitive to removing establishment status variables, suggesting manageable collinearity (Section 
S3.2). The estimation is implemented through a two-way fixed effect model with fixed effects of days and spatial units, which is a widely used modelling method to implement DiD analysis ${ }^{21}$.
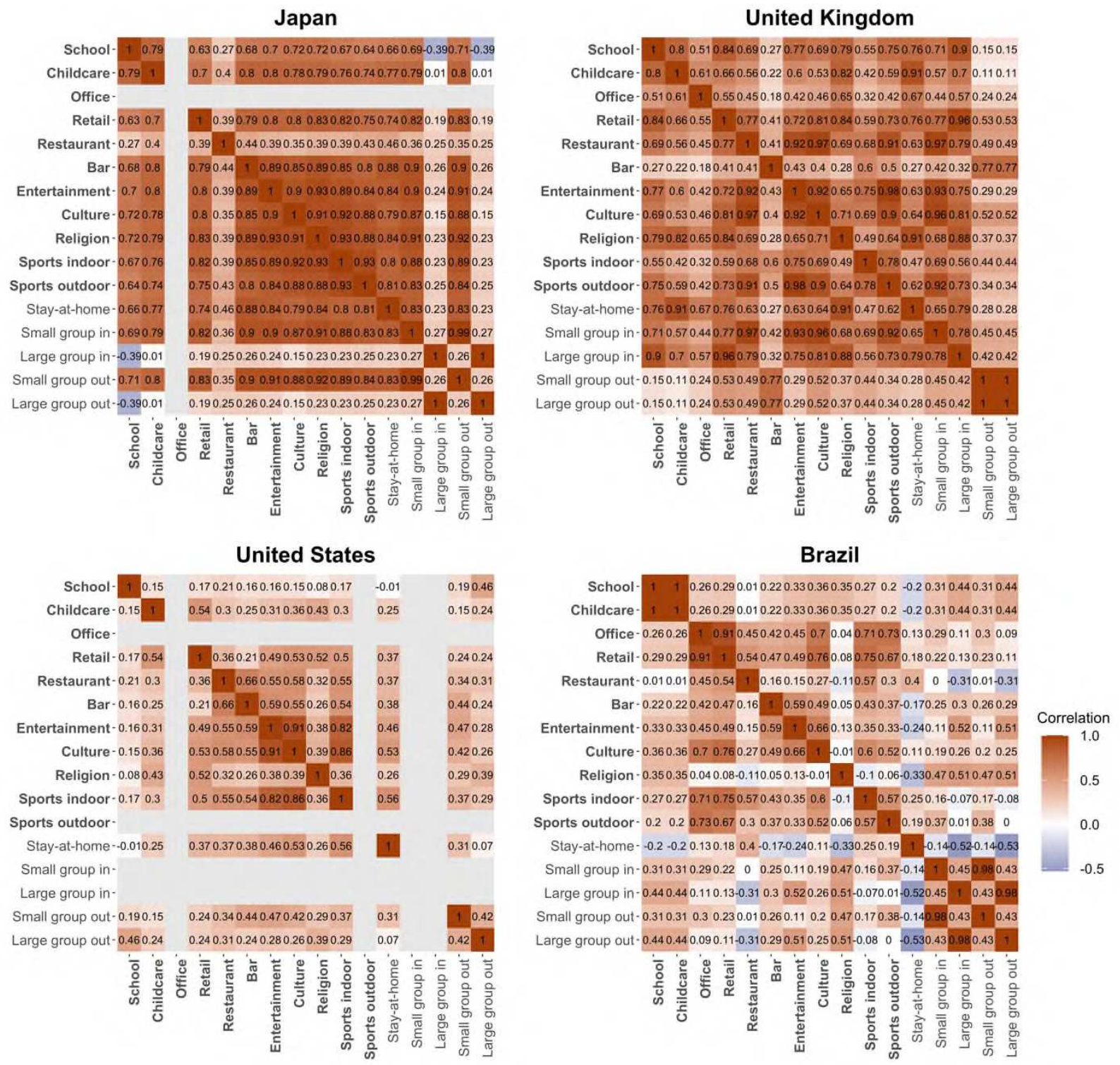

Fig. 1. Correlation between the status of establishments and other government

interventions. The matrices show pairwise Kendall's correlation coefficients between the status of establishments and other government interventions across the spatial units in each country during the study period. Bold texts indicate the establishments and regular texts are the other government interventions that we control for. Grey lines indicate that information on the corresponding intervention is missing in the country. The correlation coefficients are estimated based on samples excluding unit-day observations where the coefficient of variance for $R_{t}$ estimate is larger than 0.3 (suggesting unreliable estimates), which are 2,400 in Japan, 24,285 in the United Kingdom, 41,752 in the United States, and 34,812 in Brazil. 
To perform the analysis, we combine data from a variety of sources including COVID-19 infection case data, government intervention data, and socioeconomic characteristics of spatial units (see Section S1 for detailed description of data sources). We use data from the first pandemic wave, that is, from March to August 2020, since there could be more factors potentially biasing the analysis in later periods of the pandemic including lockdown fatigue, virus variants, vaccination, etc. ${ }^{9}$.

\section{Results}

\section{Infection risks at micro-scale activity places (establishments)}

The DiD analysis provides estimates on the percentage reduction in $R_{t}$ caused by closing each type of establishments (computed from direct model outputs as $1-e^{x}$, where $x$ denotes direct model outputs shown in Fig. 2). The reductions can be further interpreted as the proportions of total infections related to the respective type of establishments, which could happen through human interactions either inside these places or on the way to these places. Closures of establishments that show a statistically significant impact on reducing $R_{t}$ in each country are (with 95\% confidence interval): entertainment venues (53\%, 4 to $77 \%$ ) in Japan; restaurants and cultural venues (combined with indoor gathering ban whose effect is inseparable, 25\%, 5 to $41 \%)$ and indoor sports venues $(43 \%, 13$ to $63 \%)$ in the United Kingdom; entertainment venues $(17 \%, 1$ to $31 \%)$ in the United States; and non-essential retails (20\%, 9 to $31 \%)$ and indoor sports venues (36\%, 27 to 43\%) in Brazil (Fig. 2, full model results in Table S2). These results reflect the establishments with the largest epistemological risks in each country. 

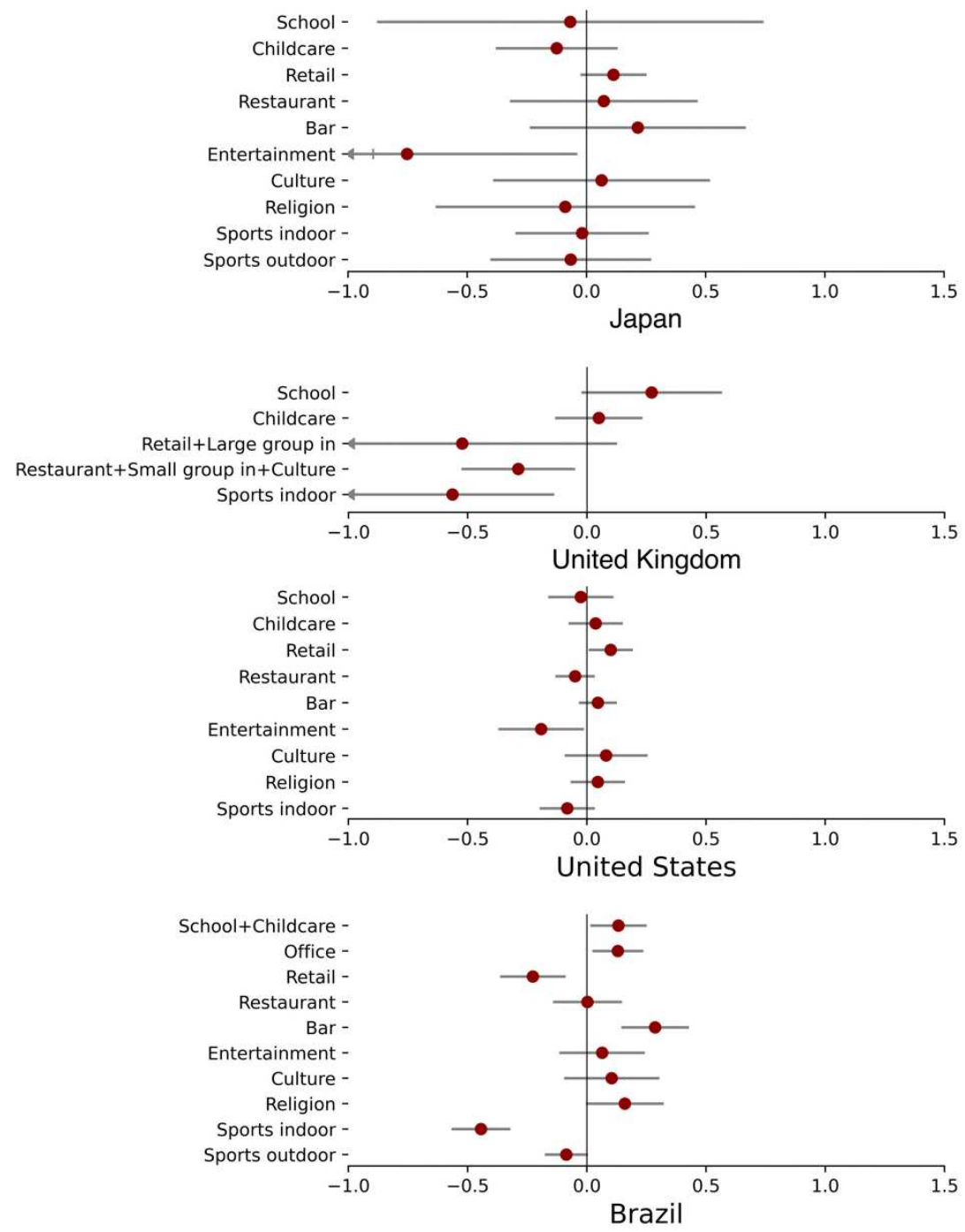

Fig. 2. Estimated impacts of closing individual types of establishments. The numbers are direct model outputs on the relationship between establishment status $(0,0.5$ or 1$)$ and $\Delta \log \left(R_{t}\right)$. Full results are presented in Table S2.

Most of the establishment status variables satisfy the parallel trend assumption, meaning that the estimates are not biased by potentially different pre-trends of $R_{t}$ in areas that close or reopen a group of establishments and those that do not (detailed methodology and results of the parallel trend test in Section S2.2 and Table S3). The estimates are also generally robust to a number of alternative settings in the analysis, including withholding spatial units from the sample and increasing or decreasing variables in the model, suggesting that they are not likely to be affected 
by individual influential spatial units and the correlation among variables (detailed methodology and results in Section S3.1 and S3.2).

Considering that epidemic response plans often need to identify a set of establishments with largest combined impact, we further estimate the joint impacts of all possible combinations of establishments in each country based on the previous results. The full results can be found in the repository of this project (see Code Availability). Here we present the maximum reduction in $R_{t}$ that can be achieved by closing a given number of establishments (Fig. 3). Our analysis suggests that the largest reductions in $R_{t}$ are achieved by closing two to six types of establishments, while more closures do not further bring reproduction numbers down. Governments could resort to this kind of analysis when making cost-effective intervention strategies. 

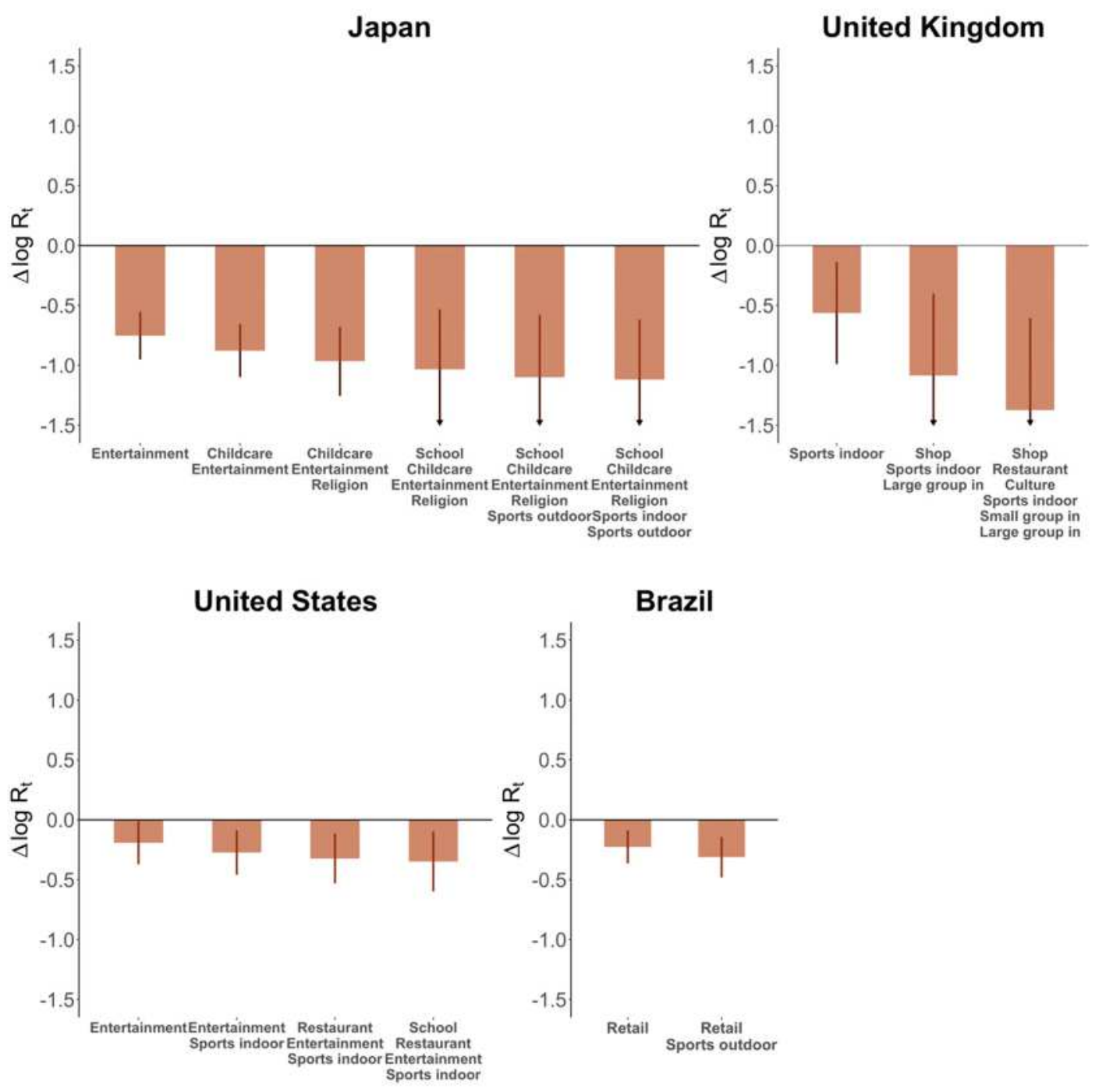

Fig. 3. Maximum joint impacts of closing a number of establishments. We show the maximum impacts that could be achieved by closing a given number of establishment types, till the maximum joint impacts are produced.

\section{Infection risks at macro-scale activity places (settlements)}

The fixed effects of spatial units in the two-way fixed effect model estimated in the previous step can be interpreted as the intrinsic speed of virus transmission in each spatial unit absence of any spontaneous or compulsory behavioral changes. This fixed effect could be a combined outcome of settlements' spatial (such as size and density) and socioeconomic characteristics such as the age, ethnicity and wealth of residents. Based on this, we estimate the impacts of settlement size 
and density on this intrinsic speed of virus transmission using a linear regression with the unit fixed effects as the dependent variable and settlement socioeconomic characteristics as control variables.

The impacts of settlements' population size and density are fairly consistent across the four countries (Table 1). Population size is negatively correlated with spatial unit's fixed effect on $R_{t}$ and this is statistically significant in three of the four countries, where the effect size ranges between $2.0 \%$ (1.1 to $3.2 \%$ ) to $4.9 \%$ (2.3 to $7.5 \%$ ) reduction of $R_{t}$ per million increase of population. The impact of density is less clear, yet none of the estimates is positively significant as suggested by the common beliefs mentioned in the introduction. These results contradict the impression that large and densely populated cities tend to be epicenters and suggest that in terms of the reproduction number, large and dense cities are not riskier, but even less. Explanations for the negative relationship between settlement size and $R_{t}$ might include better health infrastructures in large cities and people's stronger awareness of the risk thus more cautious behavior $^{22,23}$.

\begin{tabular}{lllll}
\hline Characteristics & Japan & $\begin{array}{l}\text { United } \\
\text { Kingdom }\end{array}$ & $\begin{array}{l}\text { United } \\
\text { States }\end{array}$ & Brazil \\
\hline Size & -0.118 & $-0.029 * *$ & $-0.0219^{* * *}$ & - \\
& $(0.113)$ & $(0.0111)$ & $(0.00531)$ & $\begin{array}{l}0.0506^{* * *} \\
(0.0139)\end{array}$ \\
Density & & & & $\begin{array}{l}0.0184 * * \\
\end{array}$ \\
Proportion of elderly & -0.203 & -0.00108 & 0.00453 & $-0.00648)$ \\
population & -0.102 & -0.0325 & $0.535^{* * *}$ & -0.228 \\
Proportion of Black & - & -0.105 & -0.000726 & - \\
& & $(0.425)$ & $(0.000542)$ & \\
Proportion of Asian & - & 0.162 & $0.00304 *$ & - \\
& & $(0.124)$ & $(0.00148)$ & \\
Personal income & -0.125 & - & - & $0.105 *$ \\
& $(0.105)$ & & $0.00686^{* * *}$ & $(0.0435)$ \\
& & & $(0.000926)$ &
\end{tabular}




\begin{tabular}{lllll} 
GDP per capita & 0.00494 & $-0.00123 *$ & $0.002 * *$ & -0.000228 \\
& $(0.00855)$ & $(0.000592)$ & $(0.000635)$ & $(0.000374)$ \\
(Intercept) & 0.781 & $-0.158 * *$ & $0.101 * *$ & $0.217 * * *$ \\
& $(1.68)$ & $(0.0514)$ & $(0.0386)$ & $(0.0463)$ \\
Observations & 44 & 234 & 307 & 319 \\
R-squared & 0.294 & 0.0622 & 0.345 & 0.125 \\
Adjusted R-squared & 0.198 & 0.0373 & 0.329 & 0.111 \\
\hline \multicolumn{5}{c}{$* \mathrm{p}<0.05, * * \mathrm{p}<0.01, * * * \mathrm{p}<0.001$}
\end{tabular}

Table 1. Impact of settlement characteristics on the intrinsic speed of virus spread. Results in this table are based on samples excluding outliers (Shimane in Japan, Mendip in the United Kingdom, and Indianapolis-Carmel-Anderson, Pittsfield and San Angelo in the United Sates), so that the residuals are normally distributed (Shapiro-Wilk test $\mathrm{p}>0.05$ ). Results on full samples are very similar (shown in Table S4). The variance inflation factors are all below 7.

\section{Varying risks by the interaction between the two scales}

We also examine the interaction between macro-scale settlement characteristics and micro-scale establishments in the transmission of COVID-19, since the activity pattern of residents in different types of settlements could be different, leading to heterogeneous distribution of infection risks. To do this, we re-estimate the maximum joint effects of establishment closures on separate samples of relatively large and small, and high-and low-density spatial units. The high/low samples are split by the median population size (174,980 people) and density (681 people per squared kilometer) of all sample spatial units, except for Japan where the population size and density are generally much higher so that we use the median of its own $(314,082$ people and 5,671 people per squared kilometer, respectively). More details on the specification of the models and sensitivity tests can be found in Methods and Section S3.

The comparisons are remarkably consistent across the four countries in terms of the interaction with settlement size - the impacts of establishment closures are larger in relatively small settlements, reflecting a higher share of infections accounted for by specific establishments in smaller settlements (Fig. 4A). In other words, a larger proportion of infections are related to 
general public spaces in large settlements, which might include streets, public transits, etc. ${ }^{24}$. The disparity in the proportion of infections accounted by establishments ranges between $3 \%$ and $18 \%$. The impacts are also larger in relatively low-density settlements in Japan and Brazil, and the impacts are close to each other in the United Kingdom and the United States.

To test whether the results hold when the population and density thresholds change, we repeat the analysis with a series of cut-off values between the first and third quantiles of population size and density in each country. The results are generally stable regardless of the threshold used to split the samples, and are particularly consistent in terms of settlement size: the proportion of infections accounted for by various establishments are always bigger in relatively small settlements than in large settlements in all sample countries (Fig. 4B). Similar pattern also exists with regard to settlement density in Japan and less prominently in Brazil. 
A

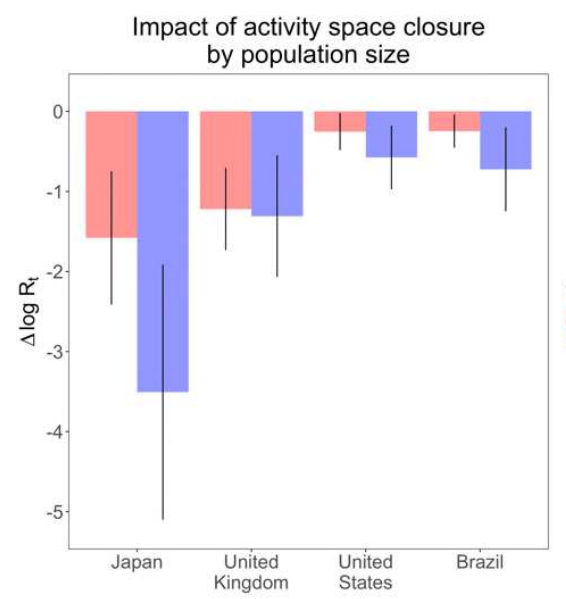

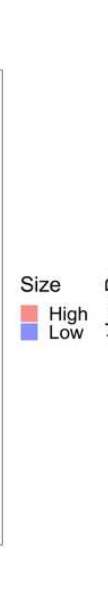

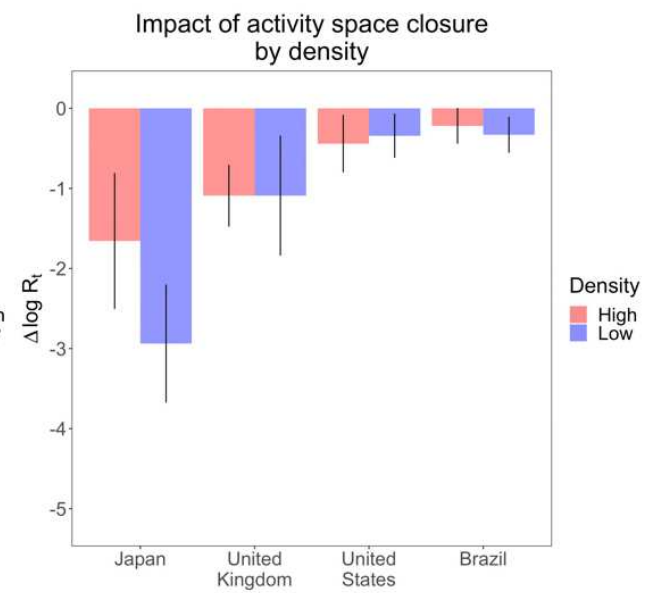

B
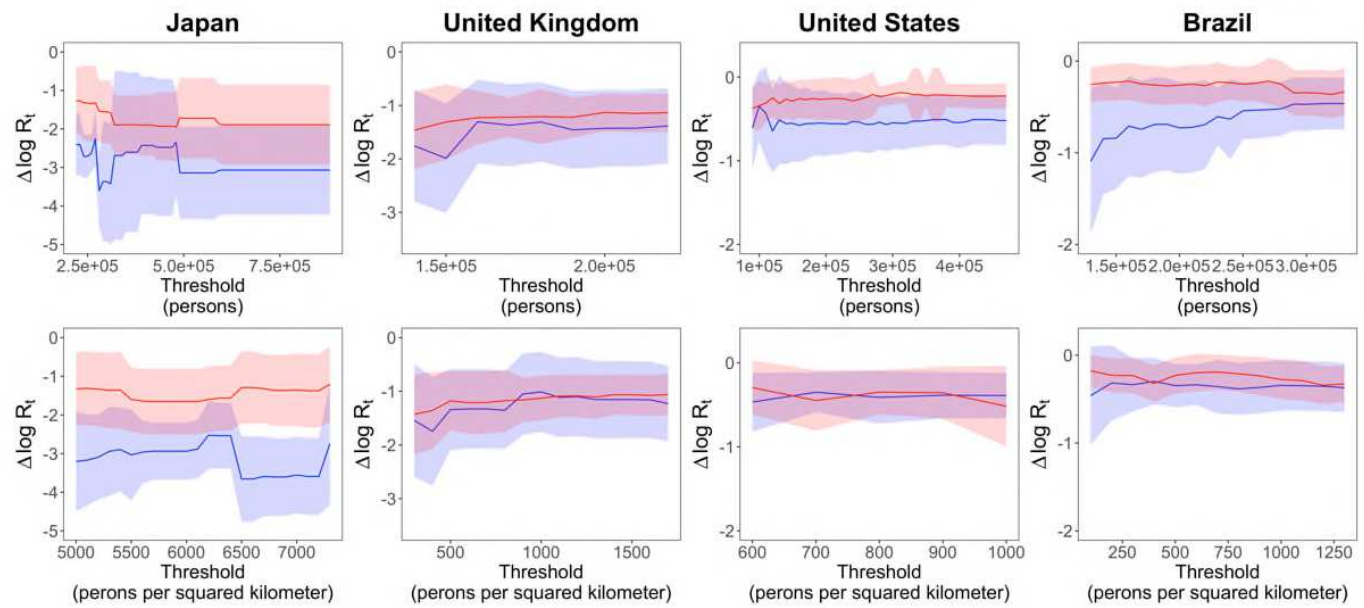

Fig. 4. Impact of establishment closures in settlements with different population size and density. The error bars and ribbons indicate $95 \%$ confidence intervals.

\section{Discussion}

Our analysis quantifies the virus transmission risks at different types of human activity places using evidences from the COVID-19 pandemic. The work contributes to an emerging literature on the health and resilience of human settlements and takes the first steps towards developing a system of knowledge on the infectiousness of activity places ${ }^{25-27}$. The results can inform minimal impact resilience plans for not only the on-going COVID-19 but also future public health crisis, as well as long-term strategy making in reducing the epistemological risks in human settlements. 
Data from COVID-19 suggests that closing various establishments could at most reduce $R_{t}$ by $27 \%$ to $75 \%$ in the four sample countries; in other words, activities at these establishments lead to $27 \%$ to $75 \%$ of all infections. The magnitudes of the impacts are heterogeneous across countries, which could be affected by the behaviors and interactions at relevant places, socioeconomic profiles of the visitors, physical conditions of relevant spaces, as well as the level of enforcement. For example, the small effect sizes in the United States and Brazil might be related to loose enforcement and non-compliance, thus might not reflect the true impact of establishments in virus transmission in the two countries ${ }^{28,29}$. The heterogeneous results suggest that while it sounds strong to draw general conclusions on the infection risks of activity places, such conclusions could run the risk of over-simplification and diverge from the reality for individual countries. Despite of the heterogeneity, it is common in the four sample countries that the closures of essential activity places including schools, childcare centers and offices do not demonstrate statistically significant effects in reducing $R_{t}$ while closing certain non-essential activity places, including sports fields, entertainment venues and restaurants, tend to be more effective. Resilience plans for future public health crisis could first consider interventions targeted at these places, which is likely to be more cost-effective.

For macro-scale settlement characteristics, our findings contradict the common belief that large and densely populated cities are more vulnerable to infectious disease ${ }^{30}$. This could either because the seemingly increased connectivity and proximity among people in large and dense cities do not actually enhance the chance for virus transmission, or such effect does exist but is offset by other positive factors such as more healthcare resources driven by economy of scale and more cautious behavior of people. The exact causal chain could also involve the 
demography, education, economy, even partisanship in different types of settlements ${ }^{23,31}$, which is subject to further study. Either way, these results lend more confidence to encouraging agglomeration of people and high-density development.

The finding that the eleven types of establishments account for a smaller proportion of infections in relatively large settlements suggests that more infections take place at public spaces other than the confined areas of establishments in large settlements, which might be explained by generally longer travel distances in large settlements thus more contacts on streets, public transits, etc. It indicates that governments could rely less on closing establishments, which is economically risky, and resort to other measures to reduce infection transmission in large cities, such as contact tracing or more intense disinfection of public spaces.

Nonetheless, our findings could be affected by a number of limitations. First, besides human activities and physical environments, the virus transmission risks are also affected by the characteristics of pathogens, including the means of transmission, the susceptible population group, etc. The findings drawn from COVID-19 might apply to respiratory infectious diseases, but might not reflect the risks associated with other infectious diseases, which would further contribute to a system of knowledge on the infectiousness of places.

Second, in terms of the causal identification strategy, the DiD method requires both parallel trend and exogeneity of the treatment. While the parallel trend assumption is examined with an eventstudy design (Section S2.2), the exogeneity assumption could be challenged by unobserved confounders that affect both $R_{t}$ and the closure of establishments. Though we are able to rule out a number of confounders by including a large set of government intervention variables as well as 
unit and day fixed effects, there could still be endogeneity arising from omitted unit-specific time-varying factors. For instance, a sudden outburst of infections in a hotspot may affect both governments' interventions and local residents' cautionary behavior which then affects $R_{t}$.

Third, since the impacts of closing different types of establishments are estimated in one model, the results could be subject to the so-called "table 2 fallacy" which refers to that the coefficients of confounders in a model are wrongly interpreted as full causal effects while they are actually only the direct effects ${ }^{32}$. This problem applies if decisions to close or reopen establishments affect each other so that they become confounders. While this is possible, we suppose such relationship should be weak since these decisions tend to be more directly affected by the trends of infections, instead of the status of other interventions.

Fourth, we assume linear relationship between $R_{t}$ and the independent variables in the entire analysis, which is a convenient assumption made by many studies on intervention effects in COVID-19 ${ }^{8,10,12,16,33}$. However, the impact of closing one type of establishment may rely on the status of other establishments, since the corresponding activities could be complementary or substitutive to each other, leading to interacting effects. It is encouraging that studies which examine nonlinear relationships and sequence of interventions do not find significant patterns $8,34,35$, but the issue cannot be ignored.

To our knowledge, this is the first work that systematically examine the role of multitype and multiscale activity places in the transmission of infectious disease. Actually, public health concerns have been a key factor in shaping the planning and management of cities as early as the time of John Snow at the advent of modern cities. Our findings show that with increased human 
agglomeration and interaction, epidemic control no longer only involves confined areas such as hospitals or the water supply system, but also the entire urban space. Improving our knowledge on the linkage between places, human activities and diseases would be important for long-and short-term policy making in public health, urban resilience and the planning of human settlement.

\section{Methods}

\section{Data}

We curate a data set combining daily infection cases, government interventions (including establishment closures, stay-at-home orders and gathering bans) and the spatial, demographic and economic characteristics of the spatial units in our study, from the onset of the pandemic till August 15 2020. The spatial units are 45 prefectures in Japan, 234 local authority districts in the United Kingdom, 308 metropolitan statistical areas in the United States and 319 municipalities in Brazil (detailed explanations on the choice of spatial units in Section S1.1-1.4). Note that prefectures (the first-level administrative division) of Japan are larger than the spatial units in other countries and contain more than one large settlement in many cases. However, infection data can only be consistently acquired at this level in $\operatorname{Japan}^{37}$, so that it is taken as the unit of analysis. Nonetheless, we prove that the choice of spatial units would not substantially affect the results (Section S3.3).

The infection case data are sourced from Japan Broadcasting Corporation's case reports, the UK government, Johns Hopkins University and the Brazilian Ministry of Health. The timetable of government interventions is manually collected from the websites of national and state-level governments, which are the main levels of authorities making decisions on interventions. The 
settlement-related information is gathered from a number of official websites. More details on data sources are provided in Section S1.

\section{Estimating impacts of closing individual types of establishments}

The causal impacts of closing individual types of establishments across all spatial units and subgroups of spatial units in a country are estimated with a two-way fixed effect model specified as follows

$$
\log \left(R_{c, i, t}\right)=\boldsymbol{\beta}_{\mathrm{c}} \boldsymbol{X}_{\mathrm{c}, \mathrm{i}, \mathrm{t}}+\boldsymbol{\theta}_{\mathrm{c}} Z_{\mathrm{c}, \mathrm{i}, \mathrm{t}}+\alpha_{c, i}+\tau_{c, t}+\varepsilon_{c, i, t}
$$

where $\log \left(R_{c, i, t}\right)$ is the $\log$-transformed instantaneous reproduction number in unit $i$ of country $c$ on day $t ; \boldsymbol{X}_{\boldsymbol{c}, \boldsymbol{i}, t}$ is a vector denoting the status of the eleven types of establishments and $\boldsymbol{\beta}_{\boldsymbol{c}}$ denotes the corresponding coefficients to estimate. We log-transform $R_{c, i, t}$ following the practice of relevant works ${ }^{10,14}$, based on the plausible assumption that the reduction of $R_{c, i, t}$ by the closure of establishments should be proportional to the proportion of contacts avoided instead of an absolute value, and the impacts should be smaller when $R_{c, i, t}$ is already low. $Z_{c, i, t}$ and $\theta_{c}$ denote the status of five other government interventions and their coefficients (detailed description of these interventions in Table S1); $\alpha_{c, i}$ and $\tau_{c, t}$ denote the unit and time fixed effects, respectively; and $\varepsilon_{c, i, t}$ denotes the error term. For the uncertainty over the parameters, we estimate robust standard errors allowing for $\varepsilon_{c, i, t}$ to cluster at the unit level, to account for heterogeneity in the treatment effects ${ }^{36}$. If the statuses of two types of establishments are highly correlated in a country (Kendall's correlation coefficients larger than 0.95), then they are treated as one combined type to avoid collinearity (Fig. 1). 


\section{Estimating joint impacts of multiple establishments}

The point estimates of the joint impacts are computed by summing the corresponding

coefficients estimated by Eq. 1: $\sum_{s \in P} \beta_{c, s}$, where $\beta_{c, s}$ denotes the coefficient of closing

establishment $s$ in country $c$ and $P$ denotes a set of establishments. The standard errors are computed from the robust standard errors and covariances as follows

$$
S E_{c, P}=\sqrt{\sum_{s \in P} S E_{c, s}^{2}+\sum_{s \in P, s^{\prime} \in P, s \neq s^{\prime}} C O V_{c, s, s^{\prime}}}
$$

where $S E_{c, P}$ denotes the standard error of the joint impacts of set $P$ in country $c ; S E_{c, s}$ denotes the robust standard error of closing establishment $s$ estimated by Eq. 1; and $C O V_{c, s, s}$ is the covariance between the impacts of establishment $s$ and $s$.

\section{Estimating impacts of macro-scale settlement characteristics}

We take the unit fixed effects estimated by Eq. 1, which can be interpreted as the intrinsic reproduction number in each spatial unit, and model their relationship with the size and density of settlements while controlling for the proportion of elder population (over 65 or 60 years old depending on data availability), proportion of Black and Asian (in the United Kingdom and the United States only), the average income of residents and the per capita gross domestic product, using simple linear regression.

$$
\begin{gathered}
\alpha_{c, i}=\sigma_{c, 1} \text { DENSITY }_{c, i}+\sigma_{c, 2} \text { POPULATION }_{c, i}+\sigma_{c, 3} \text { OLD }_{c, i}+\sigma_{c, 4} \text { BLACK }_{c, i}+ \\
\sigma_{c, 5} \text { ASIAN }_{c, i}+\sigma_{c, 6} \operatorname{INCOME}_{c, i}+\sigma_{c, 7} G D P_{c, i}+\psi_{c}+\xi_{c, i}
\end{gathered}
$$

where DENSITY $_{c, i}$, POPULATION $_{c, i}$, OLD $_{c, i}$, BLACK $_{c, i}$, ASIAN $_{c, i}, \operatorname{INCOME}_{c, i}$, GDP $_{c, i}$ denote the density, population size, proportion of elder population, proportion of Black, proportion of Asian, residents' income and per capita gross domestic product in unit $i ; \sigma_{\mathrm{c}, 1}$ to $\sigma_{\mathrm{c}, 7}$ are their coefficients; $\psi_{\mathrm{c}}$ is the constant and $\xi_{c, i}$ is the error term. 


\section{Data Availability}

The datasets analyzed during the current study are available in the Github repository, https://github.com/lunliu454/infect_place.

\section{Code availability}

All codes for analysis and visualization presented in this manuscript is available at https://github.com/lunliu454/infect_place. This work is licensed under a Creative Commons Attribution 4.0 International (CC BY 4.0) license, which permits unrestricted use, distribution, and reproduction in any medium, provided the original work is properly cited. To view a copy of this license, visit https://creativecommons.org/licenses/by/4.0/.

\section{References and Notes}

1 Bettencourt, L. M., Lobo, J., Helbing, D., Kühnert, C. \& West, G. B. Growth, innovation, scaling, and the pace of life in cities. Proc. Natl. Acad. Sci. 104, 7301-7306 (2007).

2 Glaeser, E. Cities, productivity, and quality of life. Science 333, 592-594 (2011).

3 Hamidi, S., Sabouri, S. \& Ewing, R. Does density aggravate the COVID-19 pandemic? Early findings and lessons for planners. J. Am. Plann. Assoc. 86, 495-509 (2020).

4 Ribeiro, H. V., Sunahara, A. S., Sutton, J., Perc, M. \& Hanley, Q. S. City size and the spreading of COVID-19 in Brazil. PLoS One 15, e0239699 (2020).

5 Bettencourt, L. M. The origins of scaling in cities. Science 340, 1438-1441 (2013).

6 Li, Y. et al. Probable airborne transmission of SARS-CoV-2 in a poorly ventilated restaurant. Build. Environ. 196, 107788 (2021).

7 Vuorinen, V. et al. Modelling aerosol transport and virus exposure with numerical simulations in relation to SARS-CoV-2 transmission by inhalation indoors. Saf. Sci. 130, 104866 (2020).

8 Bo, Y. et al. Effectiveness of non-pharmaceutical interventions on COVID-19 transmission in 190 countries from 23 January to 13 April 2020. Int. J. Infect. Dis. 102, 247-253 (2021).

9 Sharma, M. et al. Understanding the effectiveness of government interventions in Europe's second wave of COVID-19. Preprint at https://www.medrxiv.org/content/10.1101/2021.03.25.21254330v1.full (2021).

10 Brauner, J. M. et al. Inferring the effectiveness of government interventions against COVID-19. Science 371, eabd9338 (2021).

11 Cho, S. Quantifying the impact of nonpharmaceutical interventions during the COVID-19 outbreak: The case of Sweden. The Econometrics Journal 23, 323-344 (2020).

12 Dave, D., Friedson, A. I., Matsuzawa, K. \& Sabia, J. J. When do shelter-in-place orders fight COVID - 19 best? Policy heterogeneity across states and adoption time. Econ. Inq. 59, 29-52 (2021).

13 Dehning, J. et al. Inferring change points in the spread of COVID-19 reveals the 
effectiveness of interventions. Science 369, eabb9789 (2020).

14 Flaxman, S. et al. Estimating the effects of non-pharmaceutical interventions on COVID19 in Europe. Nature 584, 257-261 (2020).

15 Fowler, J. H., Hill, S. J., Levin, R. \& Obradovich, N. The effect of stay-at-home orders on COVID-19 cases and fatalities in the United States. Preprint at https://arxiv.org/abs/2004.06098 (2020).

16 Islam, N. et al. Physical distancing interventions and incidence of coronavirus disease 2019: Natural experiment in 149 countries. BMJ 370, m2743 (2020).

17 Singh, S., Shaikh, M., Hauck, K. \& Miraldo, M. Impacts of introducing and lifting nonpharmaceutical interventions on COVID-19 daily growth rate and compliance in the United States. Proc. Natl. Acad. Sci. 118, e2021359118 (2021).

18 Banholzer, N. et al. Estimating the effects of non-pharmaceutical interventions on the number of new infections with COVID-19 during the first epidemic wave. PLoS One 16, e0252827 (2021).

19 Batty, M. The New Science of Cities. (MIT Press, Cambridge, Mass., 2013).

20 Goodman-Bacon, A. \& Marcus, J. Using difference-in-differences to identify causal effects of COVID-19 policies. Surv. Res. Methods 14, 153-158 (2020).

21 Angrist, J. D. \& Pischke, J. Mostly Harmless Econometrics. (Princeton University Press, Princeton and Oxford, 2008).

22 Ewing, R. \& Hamidi, S. Compactness versus sprawl: A review of recent evidence from the United States. J. Plan. Lit. 30, 413-432 (2015).

23 Haischer, M. H. et al. Who is wearing a mask? Gender-, age-, and location-related differences during the COVID-19 pandemic. PLoS One 15, e0240785 (2020).

24 Harris, J. E. The subways seeded the massive coronavirus epidemic in New York City. Preprint at https://www.nber.org/papers/w27021 (2020).

25 Tian, H. et al. Urbanization prolongs hantavirus epidemics in cities. Proc. Natl. Acad. Sci. 115, 4707-4712 (2018).

26 Corburn, J. Toward the Healthy City: People, Places, and the Politics of Urban Planning. (MIT Press, Cambridge, 2009).

27 Vale, L. J. The Resilient City: How Modern Cities Recover from Disaster. (Oxford University Press, Oxford, 2005).

28 Witte, G. The Washington Post https://www.washingtonpost.com/national/coronavirusshutdowns-have-gone-nationwide-many-police-departments-arent-enforcingthem/2020/03/25/56be5ed2-6e00-11ea-a3ec-70d7479d83f0_story.html (2020).

29 Mello, G. \& Gaier, R. V. Reuters https://www.reuters.com/article/us-health-coronavirusbrazil-lockdown-idUSKCN21R30B (2020).

30 Shoichet, C. E. \& Jones, A. CNN https://www.cnn.com/2020/05/02/us/cities-populationcoronavirus/index.html (2020).

31 Gadarian, S. K., Goodman, S. W. \& Pepinsky, T. B. Partisanship, health behavior, and policy attitudes in the early stages of the COVID-19 pandemic. PLoS One 16, e0249596 (2021).

32 Westreich, D. \& Greenland, S. The table 2 fallacy: Presenting and interpreting confounder and modifier coefficients. Am. J. Epidemiol. 177, 292-298, doi:10.1093/aje/kws412 (2013).

33 Hsiang, S. et al. The effect of large-scale anti-contagion policies on the COVID-19 pandemic. Nature 584, 262-267 (2020).

34 Zhao, M., Holtz, D. \& Aral, S. Interdependent program evaluation: Geographic and social spillovers in COVID-19 closures and reopenings in the United States. Sci. Adv. 7, 
eabe7733 (2021).

35 Haug, N. et al. Ranking the effectiveness of worldwide COVID-19 government interventions. Nat. Hum. Behav. 4, 1303-1312 (2020).

36 Abadie, A., Athey, S., Imbens, G. W. \& Wooldridge, J. When should you adjust standard errors for clustering? Preprint at https://www.nber.org/papers/w24003 (2017).

37 Reustle, S. Data for covid19japan.com. https://github.com/reustle/covid19japan-data (2020).

38 National Statistics Center. Statistics of Japan (municipality data). https://www.estat.go.jp/en/regional-statistics/ssdsview/municipality (2021).

39 National Statistics Center. Statistics of Japan (prefectural data). https://www.estat.go.jp/en/regional-statistics/ssdsview/prefectures (2021).

40 National Statistics Center. National survey of family income, consumption and wealth. https://www.e-stat.go.jp/en/stat-search/filedownload?statInfId $=000032079768 \&$ fileKind $=0$ (2021).

41 Organisation for Economic Co-operation and Development. Gross Domestic Product Small regions TL3. https://stats.oecd.org (2021).

42 Office for National Statistics. Estimates of the population for the UK, England and Wales, Scotland and Northern Ireland.

https://www.ons.gov.uk/peoplepopulationandcommunity/populationandmigration/populat ionestimates/datasets/populationestimatesforukenglandandwalesscotlandandnorthernirela nd (2020).

43 Office for National Statistics. Ethnic group. https://www.nomisweb.co.uk/census/2011/ks201uk (2014).

44 Office for National Statistics. Regional gross domestic product: local authorities. https://www.ons.gov.uk/economy/grossdomesticproductgdp/datasets/regionalgrossdomest icproductlocalauthorities (2021).

45 Public Health England. Coronavirus (COVID-19) in the UK. https://coronavirus.data.gov.uk/details/download (2020).

$46 \quad$ United States Census Bureau. Metropolitan and micropolitan statistical areas population totals and components of change: 2010-2019. https://www.census.gov/data/tables/timeseries/demo/popest/2010s-total-metro-and-micro-statisticalareas.html\#par_textimage_1139876276 (2020).

47 United States Census Bureau. ua_list_all.txt. https://www2.census.gov/geo/docs/reference/ua/ua_list_all.txt (2015).

48 United States Census Bureau. Patterns of metropolitan and micropolitan population change: 2000 to 2010 (Chapter 5 data). https://www2.census.gov/programssurveys/decennial/tables/time-series/c2010sr-01/cbsa-report-chapter-5-data.xlsx (2012).

49 United States Census Bureau. American communicty survey demographic and housing estimates.

https://data.census.gov/cedsci/table?t=Race\%20and\%20Ethnicity\&g=0100000US.31000 0\&tid=ACSDP5Y2019.DP05 (2020).

50 Bureau of Economic Analysis. Personal Income by County, Metro, and Other Areas. https://www.bea.gov/sites/default/files/2020-11/lapi1120msa.xlsx (2020).

51 Bureau of Economic Analysis. Gross domestic product by metropolitan area, 2017. https://www.bea.gov/news/2018/gross-domestic-product-metropolitan-area-2017 (2018).

52 Center for Systems Science and Engineering (CSSE) at Johns Hopkins University. COVID-19 data repository. https://github.com/CSSEGISandData/COVID-19 (2020).

53 Bureau of Economic Analysis. Statistical areas. 
https://apps.bea.gov/regional/docs/msalist.cfm (2020).

$54 \quad$ Brazilian Institute of Geography and Statistics. Estimativa 2020.

https://www.ibge.gov.br/en/statistics/social/population/18448-estimates-of-residentpopulation-for-municipalities-and-federation-units.html? $=\& \mathrm{t}=$ downloads $(2021)$.

55 Brazilian Institute of Geography and Statistics. Censo demografico 2010 indicatores sociais municipais. https://ftp.ibge.gov.br/Censos/Censo_Demografico_2010/indicadores_sociais_municipais Brasil.zip (2010).

56 Brazilian Institute of Geography and Statistics. Average and median per capita household income. https://ftp.ibge.gov.br/Indicadores_Sociais/Sintese_de_Indicadores_Sociais/Sintese_de_I ndicadores_Sociais_2020/xls/2_Rendimento_xls.zip (2019).

57 Brazilian Institute of Geography and Statistics. Gross domestic product of municipalities. https://ftp.ibge.gov.br/Pib_Municipios/2018/base/base_de_dados_2010_2018_xls.zip (2018).

58 Fontes, R. Coronavirus - Brazil. https://www.kaggle.com/unanimad/corona-virus-brazil (2020).

59 Brazilian Ministry of Health. Coronavirus Brazil, <https://covid.saude.gov.br $>$ (2020).

60 Yabe, T. et al. Non-compulsory measures sufficiently reduced human mobility in Tokyo during the COVID-19 epidemic. Sci. Rep. 10, 1-9 (2020).

61 Cori, A., Ferguson, N. M., Fraser, C. \& Cauchemez, S. A new framework and software to estimate time-varying reproduction numbers during epidemics. Am. J. Epidemiol. 178, 1505-1512 (2013).

$62 \mathrm{Li}$, Q. et al. Early transmission dynamics in Wuhan, China, of novel coronavirus-infected pneumonia. N. Engl. J. Med. 382, 1199-1207 (2020).

\section{Acknowledgments}

This work is supported by the Beijing Social Science Foundation (20GLA003, L.L.), the Tsinghua University Spring Breeze Fund (2021Z99CFY038, H.W.), the National Natural Science Foundation of China (52008005, L.L.) and the Institute of Public Governance, Peking University (YQZX202005, L.L.). We thank the High-performance Computing Platform of Peking University for providing the computation resource.

\section{Author contributions}

L.L. and H.W. conceptualized the study. T.L, C.C., Y.W., R.D., C.T. and O.A. collated and cleaned the government intervention data and urban socioeconomic data. Z.Z. and W.Z. collated and cleaned the infection case data. L.L., H.W., Z.Z. and W.Z. performed the analyses. L.L. and H.W. wrote the first draft of the manuscript. L.L., H.W., S.W., E.S. revised and finalized the manuscript. 


\section{Competing interests}

The authors declare no competing interests.

\section{Materials \& Correspondence}

Correspondence to Lun Liu and Hui Wang. 


\section{Supplementary Files}

This is a list of supplementary files associated with this preprint. Click to download.

- npjSM.docx 